\title{
Team management
}

National Diabetes Information Clearinghouse (NDIC)

\section{Definitions}

Diabetes

Defined by National Diabetes Information Clearinghouse (NDIC)

Dietitian

Defined by National Diabetes Information Clearinghouse (NDIC)

Diabetes educator

Defined by National Diabetes Information Clearinghouse (NDIC)

\section{Source}

National Diabetes Information Clearinghouse (U.S.). (2009). The diabetes dictionary. [Bethesda, Md.]: U.S. Dept. of Health and Human Services, National Institutes of Health, National Institute of Diabetes and Digestive and Kidney Diseases, National Diabetes Information Clearinghouse.

A diabetes treatment approach in which medical care is provided by a team of health care professionals including a doctor, dietitian, nurse, diabetes educator, and others. The team provides information and advises the person with diabetes. 